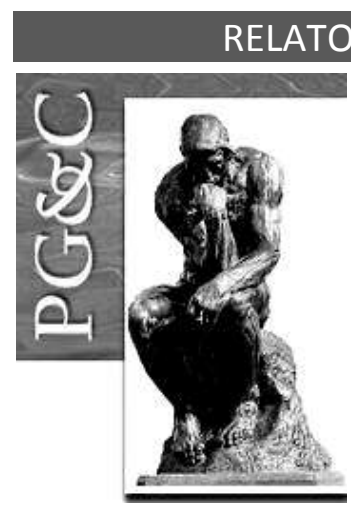

\title{
ANÁLISE DA CAPACIDADE ABSORTIVA NO PROCESSO CRIATIVO
}

\author{
Caroline Esther Buss \\ Mestre em Indústria Criativa pela Universidade Feevale, Brasil. \\ E-mail: carolinebuss@gmail.com
}

\author{
Dusan Schreiber \\ Doutor em Administração pela Universidade Federal do Rio Grande do Sul, \\ Brasil. Professor da Universidade Feevale, Brasil. \\ E-mail: dusan@feevale.br \\ Raquel Engelman Machado \\ Doutora em Administração pela Universidade Federal do Rio Grande do \\ Sul. Professora da Universidade Feevale, Brasil. \\ E-mail: raqueleng@feevale.br \\ Cristiano Max Pereira Pinheiro \\ Doutor em Comunicação Social pela Pontifícia Universidade Católica do \\ Rio Grande do Sul, Brasil. Professor da Universidade Feevale, Brasil. \\ E-mail: maxrs@feevale.br \\ Vanessa Theis \\ Doutora em Qualidade Ambiental pela Universidade Feevale, Brasil. \\ E-mail: vanessat@feevale.br
}

\begin{abstract}
Resumo
Este estudo objetiva evidenciar a capacidade absortiva no processo criativo em três agências de publicidade e propaganda localizadas na região metropolitana de Porto Alegre, no estado do Rio Grande do Sul, Brasil. Em termos metodológicos, o estudo teve abordagem qualitativa, sendo os dados coletados por meio de entrevistas em profundidade com profissionais das agências analisadas. Os resultados da pesquisa apresentam evidências de aspectos do constructo teórico da capacidade absortiva no processo criativo, bem como, permitem comparar os processos internos nas diferentes agências estudadas, cujo porte, histórico, estrutura e proposta de atuação são distintos, analisando-se as variadas práticas organizacionais para troca e compartilhamento de conhecimento, tanto interno quanto externo. Embora equipamentos e tecnologias tenham sido ressaltados como necessários para as tarefas diárias, evidenciou-se que o convívio social é o principal aspecto do ambiente de trabalho, possibilitando as interações entre profissionais com especialidades distintas e possibilitando o fortalecimento da capacidade absortiva.
\end{abstract}

Palavras-chave: Capacidade Absortiva. Processo Criativo. Indústria Criativa.

\section{ANALYSIS OF ABSORPTIVE CAPACITY IN THE CREATIVE PROCESS}

\begin{abstract}
This study aims to evidence the absorptive capacity in the creative process in three advertising agencies located in the metropolitan region of Porto Alegre, in the state of Rio Grande do Sul, Brazil. In methodological terms, the study had a qualitative approach, and the data were collected through indepth interviews with professionals from the analyzed agencies. The results of the research present
\end{abstract}

Perspectivas em Gestão \& Conhecimento, João Pessoa, v. 9, n. 3, p. 35-46, set./dez. 2019. DOI: http://dx.doi.org/10.21714/2236-417X2019v9n3p35

http://periodicos.ufpb.br/ojs2/index.php/pgc. ISSN: 2236-417X. Publicação sob Licença (cc) EY-NC-ND 
evidences of aspects of the theoretical construct of the absorptive capacity in the creative process, as well as, allow to compare the internal processes in the different agencies studied, whose size, history, structure and proposal of performance are different, analyzing the varied practices organizational knowledge sharing and exchange, both internal and external. Although equipment and technologies have been highlighted as necessary for daily tasks, it has been shown that social interaction is the main aspect of the work environment, enabling interactions between professionals with different specialties and enabling the strengthening of the absorptive capacity.

Keywords: Absorptive Capacity. Creative process. Creative Industry.

\section{INTRODUÇÃO}

Em um contexto caracterizado pela globalização, rápidas mudanças, avanços tecnológicos e acirrada competição de mercado, as empresas buscam maneiras de se destacar e renovar-se constantemente. Ao mesmo tempo em que são confrontadas com este desafio de inovar, as organizações se deparam com as limitações internas referentes ao conhecimento necessário para se destacar. Neste sentido, a capacidade de incorporar conhecimentos externos aos processos organizacionais tornou-se um fator de diferencial competitivo, visto que, à medida que a organização é capaz de aperfeiçoar sua capacidade absortiva, renova sua base de conhecimentos e melhora seu desempenho e competitividade de mercado, tornandose mais flexível e inovadora na utilização de seus recursos e capacidades.

Nesta perspectiva, a capacidade de absorção parece ser um dos mais importantes determinantes da habilidade da empresa de adquirir, assimilar e utilizar lucrativamente novas práticas de conhecimento. Desenvolver e manter a capacidade de absorção de conhecimento é fundamental para sobrevivência e sucesso de uma empresa, uma vez que, a capacidade absortiva pode reforçar, complementar ou reorientar a base de conhecimento organizacional (DAGHFOUS, 2004; LANE; KOKA; PATHAK, 2006). Contudo, acompanhar o atual processo social e cultural, extremamente dinâmico, tem se mostrado uma dificuldade para as organizações de praticamente todos os setores, e isso se reflete também na realidade do mercado publicitário, escolhido para análise na presente pesquisa.

Em decorrência da acirrada concorrência no mercado, atualmente os empresários devem confiar cada vez mais na publicidade para manter ou aumentar o volume de vendas, e consequentemente, as agências de publicidade tem experimentado um grande crescimento. Diante deste cenário, o objetivo desta pesquisa é evidenciar a capacidade absortiva no processo criativo em agências de publicidade. A investigação se deu pela observação assistemática e pesquisa documental do ambiente e materiais institucionais de três agências de Publicidade e Propaganda da região metropolitana de Porto Alegre, no estado do Rio Grande do Sul, Brasil, bem como, por meio da análise do conteúdo de entrevistas semiestruturadas, realizadas com profissionais destas agências.

Após esta introdução, o trabalho apresenta as abordagens teóricas sobre capacidade absortiva e processo criativo, seguido dos procedimentos metodológicos e discussão dos resultados. Após a descrição e apresentação do corpus pesquisado, estão descritas as considerações finais em relação aos objetivos da pesquisa.

\section{CAPACIDADE ABSORTIVA}

De acordo com Patterson e Ambrosini (2015), a capacidade de absorção permite que a empresa adquira e utilize conhecimento externo e interno, o que influencia sua capacidade de inovar e adaptar-se a seu ambiente em constante mudança, fornecendo à empresa a

Perspectivas em Gestão \& Conhecimento, João Pessoa, v. 9, n. 3, p. 35-46, set./dez. 2019. 
capacidade de ser proativa e construir várias competências, ao invés de apenas reagir ao dinamismo da indústria. Os autores Zahra e George (2002) defendem que a capacidade absortiva é formada por quatro dimensões: aquisição, assimilação, transformação e a exploração do conhecimento. Estas dimensões são diferentes e complementares, no que se refere à sua influência sobre os resultados da organização para criação de vantagens competitivas.

Zollo e Winter (2002) sinalizam que a aquisição do conhecimento se refere a capacidade de identificar e adquirir conhecimento externo. A intensidade e a rapidez com que a firma se esforça para identificar e reunir conhecimento determina a qualidade de sua capacidade de aquisição. Daghfous (2004) complementa que a assimilação é a capacidade de analisar, processar, interpretar e compreender a informação obtida de fontes externas.

A transformação do conhecimento relaciona-se com a capacidade de reconhecer informações aparentemente incongruentes e combiná-las com o conhecimento existente. Essa capacidade permite obter novos insights, facilita o reconhecimento de oportunidades e auxilia no posicionamento estratégico (ZAHRA; GEORGE, 2002; DAGHFOUS, 2004; LANE; KOKA; PATHAK, 2006). A exploração do conhecimento, refere-se à capacidade da organização refinar, expandir e alavancar as competências existentes (ZAHRA; GEORGE, 2002). A empresa possuir rotinas definidas, estruturadas e sistemáticas permite sustentar a exploração do conhecimento por períodos maiores, possibilitando explorar e incorporar o conhecimento em novos bens, sistemas e processos, gerando a criação de novas competências (ZAHRA; GEORGE, 2002; DAGHFOUS, 2004).

Ressalta-se que os autores Zahra, Filatotchev e Wright (2009) enfatizam que o conhecimento está entre os mais valiosos recursos intangíveis, uma vez que determina a oferta de produtos de uma empresa, a capacidade de conceber novas ideias, a capacidade de configurar recursos de maneira diferente e a habilidade de desenvolver e implantar estratégias inovadoras. Como resultado, a capacidade de adquirir e usar novos conhecimentos torna-se de vital importância para a empresa. Neste sentido, Leal-Rodríguez, Ariza-Montes, Roldán e LealMillán (2014) destacam que a capacidade de absorção, depende da fonte de conhecimento e do conhecimento prévio, e está condicionada aos regimes de apropriabilidade e influencia o desempenho inovador da empresa.

O conhecimento prévio inclui as atividades de pesquisa e desenvolvimento, o capital humano e capacidades individuais, a estrutura organizacional e práticas administrativas, bem como os tipos de interações e cooperações com parceiros externos, logo, sem conhecimento prévio, as organizações não são capazes de avaliar as novas informações e, portanto, não conseguem absorvê-las (ZAHRA; GEORGE, 2002; LANE; KOKA; PATHAK, 2006; TODOROVA; DURISIN, 2007). A capacidade absortiva está baseada no acúmulo de experiência, que deve ser articulada e codificada em conhecimento (ZAHRA; GEORGE, 2002; LANE; KOKA; PATHAK, 2006).

Duas ideias relacionadas estão implícitas na noção de que a capacidade de assimilar a informação é uma função da riqueza da estrutura de conhecimento preexistente: o aprendizado é cumulativo e o desempenho de aprendizagem é maior quando o objeto de aprendizagem está relacionado com o que já é conhecido (COHEN; LEVINTHAL, 1990). A aprendizagem organizacional desempenha, portanto, um papel importante no desenvolvimento da capacidade de absorção. Para desenvolver uma capacidade efetiva de absorção, seja para conhecimentos gerais ou habilidades de resolução de problemas ou aprendizado, não é suficiente apenas expor um indivíduo de forma breve ao conhecimento prévio relevante (COHEN; LEVINTHAL, 1990). As empresas precisam de um compromisso da alta administração para criar uma organização de aprendizagem (DAGHFOUS, 2004).

Os aurores Hughes et.al. (2014), corroboram que, uma empresa que deseja melhorar sua capacidade de absorção precisa investir no desenvolvimento da capacidade de absorção de seus funcionários por meio de atividades como treinamento. Como resultado, as capacidades

Perspectivas em Gestão \& Conhecimento, João Pessoa, v. 9, n. 3, p. 35-46, set./dez. 2019. 
de absorção individuais são alavancadas, e a capacidade de absorção da organização é reforçada. Empregados com níveis mais altos de educação em uma determinada área geralmente são mais capazes de absorver novos conhecimentos nesse campo.

Enkel, E., \& Heil, S. (2014). Preparing for distant collaboration: Antecedents to potential absorptive capacity in cross-industry innovation. Technovation, 34(4), 242-260.

Na percepção de Enkel e Heil (2014), o ambiente de conhecimento externo é crucial para a capacidade de absorção. A empresa não existe sozinha, mas sim, relaciona-se com diversos atores do ambiente em que coexiste. Uma empresa criadora de conhecimento opera em um sistema aberto, no qual interage constantemente com seu ambiente externo. Em detrimento desta realidade, Todorova e Durisin (2007), Zahra, Filatotchev e Wright, (2009), destacam que não apenas a assimilação do conhecimento, mas também os outros componentes da capacidade absortiva, como a capacidade de identificar novos conhecimentos externos, requerem investimentos em redes sociais e iniciativas de integração social .Os autores Schlagwein, e Hu (2017) destacam que os mecanismos de integração social, que constroem conectividade e significados compartilhados, influenciam todos os processos de absorção do conhecimento

O conhecimento externo pode ser obtido pela união de alianças, contratação seletiva de pessoal-chave, mudança na composição ou nos processos de tomada de decisão do conselho de administração de uma empresa ou investimento em atividades de pesquisa e desenvolvimento (ZAHRA; FILATOTCHEV; WRIGHT, 2009). Ebers e Maurer (2014), sinalizam que um determinante externo importante da capacidade de absorção de uma empresa é a força de suas relações com outros membros das redes de conhecimento, o que pode incluir instituições de conhecimento como participantes primários, que podem ser suporte técnico, instituições acadêmicas e consultores.

Os autores Cohen e Levinthal (1990) e Daghfous, 2004) enfatizam que as empresas devem encorajar os funcionários a se comunicar além das fronteiras funcionais, a pensar em ideias de novos produtos e a identificar e resolver problemas compartilhados como uma equipe. Além disto, o compartilhamento do conhecimento pode ser favorecido pela adoção de práticas de gestão de recursos humanos que incluem grupos de trabalho interdisciplinares, círculos de qualidade, sistemas para a coleta de propostas de funcionários, rotatividade de trabalho planejada, delegação de responsabilidade, integração de funções e remuneração e recompensas relacionadas ao desempenho, que podem melhorar a capacidade de absorção motivando a aprendizagem contínua e facilitando a transferência de conhecimento dentro da empresa.

\section{PROCESSO CRIATIVO}

A criatividade de um grupo depende da propensão à criatividade de cada um dos seus membros. Nas organizações as ideias vêm por intuição, por aprendizagem no modelo tentativa e erro, ajustamentos progressivos motivados por oportunidades de mercado, conflitos, cooperação, entre outros (DE MASI, 2005). É provável que um bom grupo pode potencializar as capacidades de um indivíduo criativo, que não seja capaz de idealizar da mesma forma sozinho, mas por outro lado, certamente um mau grupo pode bloquear a criatividade dos indivíduos que dele fazem parte.

Neste sentido, muitas empresas investem em atividades de formação para recuperar e cultivar a disposição para a criatividade. Entretanto, na criatividade de grupo não se deve considerar apenas as capacidades criativas individuais, pois os processos e produtos serão influenciados pela interação entre os membros do grupo (DE MASI, 2005). Daghfous (2004) ressalta que, muitas vezes, o motivo para o esgotamento do grupo criativo é a entropia gerada

Perspectivas em Gestão \& Conhecimento, João Pessoa, v. 9, n. 3, p. 35-46, set./dez. 2019. 
pela burocratização das organizações. Assim, Florida (2011) enfatiza que horários, regras e códigos organizacionais, devem ser flexibilizados para atender o processo criativo.

Para Hennessey e Amabile (2010), os indivíduos são muito mais do que seus afetos, cognição ou treinamento, e os ambientes ou grupos sociais podem estar inseridos em culturas ou sociedades particulares. O humor positivo leva ao pensamento expansivo, brincalhão, divergente e a geração de novas ideias, ao passo que o humor negativo indica que algo é problemático e força os indivíduos para tentarem melhorar as questões por meio de ideias. 0 resultado de ambos os processos são ideias boas e bem planejadas, realmente criativas.

Além disto, o ambiente social pode influenciar significativamente a motivação de um indivíduo para fazer uma atividade, o que, por sua vez, influencia significativamente o desempenho criativo (HENNESSEY; AMABILE, 2010). Este é o princípio da motivação intrínseca da criatividade, definida como o impulso de fazer algo para o prazer, o interesse e o desafio pessoal da própria tarefa, e não para algum objetivo externo. A motivação é essencial para a criatividade, e diversos estudos apontam que somente é intrinsicamente motivado aquele que realmente ama o que faz, conseguindo se empenhar e enxergar o seu potencial (STERNBERG, 2006).

A segurança psicológica, uma condição ambiental em que as pessoas acreditam que os outros em seu grupo responderão positivamente quando falam sobre preocupações, cometer erros ou propõem novas ideias, é outro aspecto do ambiente de trabalho que pode ser importante na criatividade organizacional (HENNESSEY; AMABILE, 2010). Neste contexto, o brainstorming desponta como uma ferramenta amplamente utilizada para incentivar pessoas a discutir ideias criativas em grupo em busca de soluções (SIMONTON, 2000).

Os autores Hennessey e Amabile (2010) enfatizam que a autonomia no trabalho, feedback, monitoramento de trabalho e avaliação do trabalho estão intimamente relacionados e podem ter efeitos bastante diferentes sobre a criatividade, dependendo da forma como são operacionalizados. Neste contexto, Ben-Oz e Greve (2015) complementam que algumas pessoas permitem que forças negativas, como um feedback não favorável, bloqueiem seu pensamento criativo. Os autores resumem que restrições de tempo e pressões no ambiente de trabalho são prejudiciais para a criatividade, enquanto os apoios de toda a organização, segurança psicológica, tempo suficiente, autonomia, feedback de desenvolvimento e objetivos de criatividade são facilitadores.

Cumpre destacar que os processos psicológicos influenciam a cultura, a cultura influencia os processos psicológicos, os pensamentos e ações dos indivíduos têm o potencial para influenciar as normas culturais, e essas normas e práticas culturais influenciam os pensamentos e as ações dos indivíduos (HENNESSEY; AMABILE, 2010). Os efeitos da cultura sobre a criatividade são complexos e altamente interativos, e incluem fatores transversais históricos, societários e individuais. Segundo Hennessey e Amabile (2010), a exposição a múltiplas culturas pode, por si só, melhorar o comportamento criativo, ou seja, a amplitude da experiência multicultural está positivamente relacionada à criatividade em processos de desempenho e pensamentos considerados propícios ao comportamento criativo.

Por fim, ressalta-se que embora o conhecimento especializado possa ser útil na geração de estruturas pré-preventivas, é certamente melhor aproveitado quando essas estruturas são posteriormente exploradas. Há evidências consideráveis de que o desempenho criativo está vinculado à especialização em um campo específico, o que permite que a pessoa recupere informações relevantes e reconheça quando uma nova ideia é válida ou significativa (WARD; SMITH; FINKE, 1999), mas o conhecimento especializado pode ser mais útil quando aplicado em conjunto com princípios gerais para gerar e explorar estruturas pré-preventivas.

Perspectivas em Gestão \& Conhecimento, João Pessoa, v. 9, n. 3, p. 35-46, set./dez. 2019. 


\section{MÉTODO}

Esta pesquisa caracteriza-se como estudo de casos múltiplos, uma vez que se dedica ao estudo de mais de um caso, permitindo a realização de um estudo comparativo entre os casos. Para Yin (2015) a preferência pelo uso do estudo de caso deve ser no estudo de eventos contemporâneos, em situações onde os comportamentos relevantes não podem ser manipulados, mas onde é possível se fazer observações diretas e entrevistas sistemáticas. Dentre as aplicações para o estudo de caso citado por Yin (2015), procurou-se descrever o contexto da vida real de forma exploratória e descritiva. Em atendimento à recomendação de autores que versam sobre o método de estudo de caso, com destaque ao Yin (2015), os pesquisadores realizaram a triangulação de dados, por meio de entrevista em profundidade, levantamento documental e observação não participante.

O instrumento de coleta de dados foi elaborado contemplando as categorias capacidade absortiva e processo criativo. Na primeira categoria questionou-se: De que forma ocorre a busca de conhecimento externo? De que forma e com qual frequência é operacionalizada a discussão de problemas e busca de novas conexões? De que forma e em que momentos é compartilhado o conhecimento entre os integrantes da equipe? Com relação ao processo criativo, demandou-se aos entrevistados: Como o ambiente de trabalho the permite condições para o desempenho de suas atividades? O que você costuma fazer para se inspirar ou quando sente que está com bloqueio para produção criativa? Como são tratados os pensamentos divergentes até chegar ao consenso?

As entrevistas foram realizadas com dois profissionais em cada agência, tal escolha se deu com o intuito de conceber maiores condições de análise das percepções do ambiente de trabalho dos entrevistados, considerando formação e atuação em áreas do conhecimento distintas. O número reduzido se deve ao fato de uma das agências analisadas, a Agência $C$, possuir um quadro enxuto de colaboradores, limitado basicamente aos três sócios fundadores e alguns estagiários, periodicamente. As entrevistas foram realizadas no mês de outubro de 2018. Na Agência A foi entrevistada a Coordenadora administrativa Sandra, de 39 anos, que trabalha há nove anos na agência e seu colega Publicitário Eduardo, de 50 anos, há 9 meses funcionário da Agência A. Na Agência B foram respondentes a Sócia fundadora Inara, de 52 anos, atuando na área de gestão, e Thomas, de 24 anos, diretor criativo há 7 meses na agência. $\mathrm{Na}$ Agência C foram entrevistados os dois sócios fundadores, Marcelo e Fabiano, de 50 e 48 anos de idade, respectivamente, ambos publicitários e atuando juntos na criação e na gestão da Agência $C$.

O levantamento documental procedeu-se com base os sites institucionais de cada agência, folders. A observação não participante, por seu turno, ocorreu por meio da visita às instalações das empresas, que facultou aos pesquisadores observar a realização de diversas rotinas organizacionais. Desta forma também foi possível reconhecer vários dos processos e práticas internalizadas pelos colaboradores no desempenho de suas funções. 0 quadro 1 , a seguir, apresenta resumidamente os dados obtidos por meio de cada técnica utilizada.

Quadro 1 - Dados obtidos em cada técnica de coleta de dados

\begin{tabular}{|c|l|l|}
\hline Técnica & \multicolumn{1}{|c|}{ Materiais/Locais analisados } & \multicolumn{1}{c|}{ Dados coletados } \\
\hline Pesquisa documental & $\begin{array}{l}\text { Sites institucionais, folders, } \\
\text { painéis }\end{array}$ & $\begin{array}{l}\text { Valores organizacionais, histórico, } \\
\text { portfólio de produtos }\end{array}$ \\
\hline $\begin{array}{c}\text { Observação não } \\
\text { participante }\end{array}$ & $\begin{array}{l}\text { Visita in loco nas agências, análise } \\
\text { dos respondentes durante as } \\
\text { entrevistas }\end{array}$ & $\begin{array}{l}\text { Aspectos do ambiente } \\
\text { organizacional, comunicação e } \\
\text { relacionamento interpessoal dos } \\
\text { colaboradores }\end{array}$ \\
\hline
\end{tabular}

Perspectivas em Gestão \& Conhecimento, João Pessoa, v. 9, n. 3, p. 35-46, set./dez. 2019. 


\begin{tabular}{|l|l|l|}
\hline Entrevistas & $\begin{array}{l}\text { Realizada com dois colaboradores } \\
\text { de cada agência }\end{array}$ & $\begin{array}{l}\text { Dados relacionados ao processo } \\
\text { de capacidade absortiva e } \\
\text { processo criativo de cada agência }\end{array}$ \\
\hline
\end{tabular}

Fonte: Elaborado pelos autores

A técnica para análise de dados utilizada no estudo foi a de análise de conteúdo, Bardin (2009) pondera que este método consiste em procedimentos para levantar inferências válidas a partir do texto, buscando classificar palavras, frases, ou mesmo parágrafos em categorias de conteúdo. As três agências de publicidade foram escolhidas considerando amostra por acessibilidade, por serem da rede de relacionamentos dos pesquisadores.

A Agência A foi fundada em 2007 e possui unidades em Novo Hamburgo, no estado do Rio Grande do Sul e São Paulo e possui aproximadamente cem colaboradores. Localizada na região central do município de Novo Hamburgo, a Agência B é uma das mais antigas do segmento na região, somando trinta e dois anos de existência. Possui atualmente onze funcionários em seu quadro operacional. A Agência C localiza-se em Porto Alegre, no estado do Rio Grande do Sul e foi constituída há três anos. Possui três sócios-diretores que atendem as demandas da agência. Contam apenas com um estagiário e um trabalhador autônomo na equipe, que atua respectivamente na criação e na gestão de mídias digitais. Terceirizam as atividades financeiras e administrativas com profissional que atende duas vezes por semana na agência.

\section{DISCUSSÃO DOS RESULTADOS}

Incialmente, buscou-se entender como ocorre a busca de conhecimentos externos. Todorova e Durisin (2007) destacam que a capacidade de reconhecer o valor do novo conhecimento externo é um componente importante da capacidade absortiva, e esta capacidade precisa ser incentivada para que a absorção inicie. A coordenadora administrativa da Agência $A$, salientou a participação dos colaboradores em feiras e workshops, sendo as experiências e conhecimentos obtidos compartilhados com os demais colaboradores.

Ademais, como o quadro de funcionários é composto por jovens, várias das contribuições advém do meio acadêmico o qual frequentam, o que vai ao encontro do exposto por Daghfous (2004) quando este cita que um determinante externo importante da capacidade de absorção empresarial é a força das relações com membros externos de sua rede de conhecimentos, como as instituições acadêmicas.

Seu colega líder criativo relatou que costuma fazer uma reunião semanal de criação com sua equipe, para discutir assuntos relativos à criatividade, processos e clientes. Citou ainda que compartilham seus conhecimentos constantemente no dia a dia, por meio de novidades e notícias interessantes.

Na Agência B, a sócia sinalizou que a pesquisa de referências é toda feita na internet. Além de participar de cursos e congressos, os colaboradores buscam informações por meio de pesquisas, para atender necessidades específicas. $O$ colaborador da área criativa elencou que durante seu período na agência, participou de um encontro promovido pela Localweb, e que ao retornar fez uma reunião com a equipe a fim compartilhar as informações obtidas. Ele relatou ainda que troca constantemente referências de conteúdos interessantes, expostas na internet, com uma colega de criação e planejamento.

$\mathrm{Na}$ Agência C, um dos sócios comentou que o conhecimento externo entra na agência pela forma de trabalho, com equipes flutuantes formadas por prestadores de serviços terceirizados e de áreas diversas, irrestritas à publicidade, como empresas de tecnologia e novas mídias. O outro sócio entrevistado, aponta que buscam referências na internet, a fim de inteirar-se sobre o que está acontecendo no mercado. Ele, particularmente, busca referências

Perspectivas em Gestão \& Conhecimento, João Pessoa, v. 9, n. 3, p. 35-46, set./dez. 2019. 
visuais e conceituais em anuários e sites específicos, conhecimentos atrelados ao marketing, chamado por ele de conhecimento técnico, mas alerta que é necessário ao criativo buscar conhecimento vasto, sobre outras área, bem como sobre o que está sendo comentado pelas pessoas e finaliza dizendo que o criativo tem que ser curioso e entender de outras áreas.

As quatro dimensões da capacidade absortiva, conceituadas por Zahra e Gerge (2002) são a aquisição, a assimilação, a transformação e a exploração do conhecimento. A capacidade de aquisição pôde ser percebida pelos esforços das agências analisadas na busca por conhecimento externo relevante para as suas operações, como a participação em eventos e a interação com profissionais do mercado, sendo que a Agência $A$ apresentou maiores iniciativas neste sentido. Assimilação é a capacidade de analisar, processar, interpretar e compreender as informações obtidas em fontes externas, o que ocorre nos momentos de internalização dos conhecimentos, como quando os colaboradores voltam de feiras e eventos e compartilham com seus colegas os conhecimentos obtidos, exemplos citados nas agências A e B.

Quando questionados sobre a forma e com qual frequência é operacionalizada a discussão de problemas e a busca de novas conexões, por meio de brainstorming, por exemplo, na Agência A a coordenadora entrevistada diz que realizam, na área administrativa, reuniões semanais para discussão de pautas internas do setor tático. Organizam periodicamente workshops com assuntos para compartilhamento de informações, citando exemplo da empresa de serviços jurídicos da agência que palestrou aos colaboradores sobre proteção de dados, o que novamente reforça o exposto por Daghfous (2004) sobre a importância das relações com membros externos, que inclui suporte técnico e consultores.

O conhecimento prévio, que inclui as capacidades individuais bem como o tipo de interação interna e externa, influencia a avaliação de novos conhecimentos e está vinculado à capacidade de absorção, já que esta se baseia no acúmulo de experiências que devem ser articuladas e codificadas em conhecimento (ZAHRA; GEORGE, 2002; LANE; KOKA; PATHAK, 2006) e oportunidades, como a citada pelo entrevistado. Zahra e George (2002) e Lane, Koka e Pathak (2006) destacam que o sucesso de novos conhecimentos criados, pode alterar modelos mentais e ajudar na evolução das estruturas e nos processos organizacionais.

A sócia da Agência B mencionou que fazem brainstorming sempre que alguém propõe um tema ou uma necessidade surge, onde eles dividem opinião, conversam e discutem, definindo posicionamento e estratégia diante da questão. $O$ diretor da mesma agência diz que a troca de conhecimentos e a discussão são constantes, sempre na busca pela melhor solução para as demandas dos clientes, e que a interação com a equipe não se limita ao ambiente de trabalho, ocorrendo também via mídias digitais, como WhatsApp e Instagram. Na Agência C, um dos sócios entrevistados citou que quando relacionado a uma demanda mais complexa, como uma campanha, ocorre um brainstorming para planejamento e outro para criação, e quando algo mais importante é feito externamente, também fazem um brainstorming de briefing com a equipe externa.

A dimensão da capacidade absortiva de transformação denota a capacidade da empresa de desenvolver rotinas para facilitar a combinação de conhecimentos existentes a outros, interpretando-os de maneira diferente (ZAHRA; GEORGE, 2002; LANE; KOKA; PATHAK, 2006). A exploração do conhecimento, permite às empresas alavancar suas competências por meio da incorporação dos conhecimentos transformados em seus processos internos, para aplicação e exploração comercial, definindo rotinas, estruturas e sistemáticas que sustentem essa exploração (ZAHRA; GEORGE, 2002). Tais rotinas podem ser observadas no teor das entrevistas realizadas em todas as agências analisadas, pois buscam em momentos de brainstorming discutir problemas, compartilhar conhecimentos e experiências, com o propósito de construir soluções inovadoras.

Com relação a categoria de perguntas relacionada ao processo criativo, inicialmente indagou-se como o ambiente de trabalho condiciona o desempenho das atividades de cada

Perspectivas em Gestão \& Conhecimento, João Pessoa, v. 9, n. 3, p. 35-46, set./dez. 2019. 
entrevistado. Na Agência A, ambos entrevistados citam a flexibilidade de horário e local de trabalho como algo positivo, o que corrobora o exposto por Florida (2011) que defende que horários, regras e códigos organizacionais devem ser flexibilizados para atender o processo criativo. O líder criativo respondeu que a Agência $A$ é um lugar privilegiado na questão de estrutura, contando com inúmeros espaços para realização de reuniões, com equipamentos para pesquisa na internet e quadros para escrever, um ambiente aconchegante, internet em todos os locais e estrutura técnica boa e liberdade para integrar os setores na resolução de demandas do processo criativo.

A sócia fundadora da Agência $B$, diz que há trinta e dois anos a empresa busca bom humor em seu ambiente de trabalho e declara que há total liberdade para diálogo e exposição de problemas, incentiva-se o feedback e um ambiente leve de trabalho, o que retoma ao exposto por Hennessey e Amabile (2010), que dizem que o humor positivo leva ao pensamento expansivo, divergente e à geração de novas ideias. Por outro lado, o diretor criativo da agência $B$, relata que há uma grande quantidade de demanda, que a falta de tempo é prejudicial na proposta de materiais mais criativos. Hennessey e Amabile (2010) destacam que restrições e pressões no ambiente de trabalho são prejudiciais para a criatividade, como a falta de tempo suficiente para a resolução das tarefas, enquanto autonomia e feedback de desenvolvimento são facilitadores.

Para o sócio criativo e de gestão da Agência $C$, o fato de estar no ambiente de trabalho interfere apenas na possibilidade de troca de ideias, apenas para interação com a equipe, e não por fatores estruturais. Tal alegação vai ao encontro do que diz De Masi (2005), ao ressaltar que na criatividade de grupo não se deve considerar apenas as capacidades criativas individuais, pois os processos e produtos são influenciados pela interação entre os membros do grupo.

As perguntas seguintes procuraram evidenciar a manifestação da inspiração para realizar tarefas e o que os respondentes fazem quando estão com bloqueio na produção criativa. Na Agência A, o líder criativo diz que costuma dar um passo para trás quando vê que a equipe chegou num impasse. Costumam chamar mediadores para auxiliar no avanço do processo criativo, instigando formas alternativas de investigar e analisar a demanda em questão. Quando nem assim há resolução do impasse, o líder comentou que orienta sua equipe a abandonar a ideia inicial e começar novamente.

$\mathrm{Na}$ Agência $\mathrm{B}$, a entrevistada diz que a criatividade não tem método. Buscam-se outros tipos de conhecimento que ajudam na construção de coisas diferentes, como outros interesses e conhecer novas culturas e outros hábitos por meio de viagens, para não ter preconceito com nada. Quanto ao bloqueio criativo, ela citou que às vezes exige-se muito de si, sem necessidade. Defende que quando não se consegue resolver uma questão é necessário desligar-se e não ter uma rigidez muito grande, se permitir relaxar, que no dia seguinte costuma conseguir resolver os problemas de uma maneira mais simples.

O diretor criativo da Agência B respondeu que tenta se libertar da demanda, deixandoa para outro momento, quando possível. Gosta de tocar violão ou assistir a algo que possa inspirar, ressaltando que em momentos de descontração sua necessidade criativa costuma vir naturalmente. Falou que quando tem insights, faz registro de suas ideias em anotações. Tal hábito exemplifica uma rotina da fase de transformação, conceituada na capacidade absortiva pelos autores Zahra e George, (2002) Daghfous (2004) e Lane, Koka e Pathak, (2006), que diz que em tal dimensão desenvolvem-se rotinas a fim de facilitar a combinação de conhecimentos existentes a outros.

Na Agência C, um dos sócios fundadores busca referências em livros de criação que a agência tem em seu acervo, sites de campanhas mundiais e de referência estética. Usa muito o Pinterest para pesquisas e disse que como tem bastante experiência, sempre consegue resolver suas demandas criativas. Segundo Ward, Smith e Finke (1999), as ideias criativas

Perspectivas em Gestão \& Conhecimento, João Pessoa, v. 9, n. 3, p. 35-46, set./dez. 2019. 
surgem de combinações não convencionais de ideias familiares e requerem um rico histórico de conhecimento, dos mais variados, o que pode ter permitido ao profissional alegar que tem certa facilidade na resolução de demandas de trabalho criativas.

Seu sócio defende que o segredo é entender particularmente seu processo criativo, que valida o exposto por Simonton (2000) ao afirmar que evidências mostram que a criatividade requer treinamento e práticas sistemáticas para se desenvolver e que no decorrer do tempo geram o conhecimento. Para ele, inicia-se com absorção de muita informação, depois maturação dessas informações, com foco na necessidade relatada pelo cliente, e por fim, disse que só se senta na máquina para escrever ou desenvolver quando já sabe o que fazer.

A partir da análise de dados, foi possível perceber que os profissionais concentram seus conhecimentos e especialidades em demandas específicas, necessidades internas ou solicitações dos clientes, e prezam pelo compartilhamento de experiências e conhecimentos, acreditando que assim é possível explorar as potencialidades individuais e inovar. Este aspecto ficou ainda mais evidente nas respostas do entrevistado na Agência $A$, que descreveu claramente o intuito de construir equipes multidisciplinares e com perfis complementares.

Viu-se que o trabalho criativo realizado nas agências de propaganda se orienta para a resolução das necessidades demandadas pelos clientes e que a liberdade criativa se limita ao permitido pelos mesmos, mais do que pela hierarquia organizacional e autonomia concedida pelas agências, e condiciona-se ainda ao fator tempo disponível para criação. Conhecimentos e técnicas, aliados ao uso das tecnologias, são salientados como fundamentais para possibilitar as entregas nos prazos previstos. Florida (2011) defende que a criatividade deve ser promovida pelos empregadores, mas também pelos próprios indivíduos criativos e pelo contexto social em que convivem, e percebeu-se que muitos dos criativos entrevistados mantem projetos paralelos ou hobbies, que os inspiram em momentos fora do trabalho.

\section{CONSIDERAÇÕES FINAIS}

A necessidade de se tornar mais competitivas tem feito com que as organizações busquem soluções que contribuam para se adaptarem rapidamente, adotando estruturas alternativas, como a identificada na Agência $C$, que possui estrutura fixa enxuta e organiza-se conforme as demandas são geradas pelos clientes. As vantagens competitivas, fundamentais para a formulação de estratégias de sucesso em negócios, podem ser concebidas por meio de aspectos relacionados às capacidades organizacionais de aprendizado e reconfiguração dos recursos, visando gerar inovações que destaquem as organizações. A capacidade da empresa de aprender com as experiências vivenciadas evidencia que as empresas voltadas ao aprendizado apresentam cultura organizacional caracterizada pela flexibilidade, criatividade e orientação por tarefas, resolvendo problemas de forma não convencional, conforme foi possível observar, as agências estudadas apresentam esforços na obtenção deste diferencial.

Embora equipamentos e tecnologias tenham sido ressaltados como necessário para as tarefas diárias nas agências, percebe-se pelas respostas dos entrevistados e através da observação assistemática que o convívio social é o principal aspecto do ambiente de trabalho, possibilitando as interações entre pofissionais com especialidades distintas. O conhecimento prévio aliado à busca por conhecimento externo crítico se destacam como as formas mais comuns para inspiração em atividades de criação, e as empresas estudadas buscam a obtenção deste conhecimento em sua interação com o mercado, com clientes e profissionais, bem como, em eventos, na internet e até mesmo no ambiente acadêmico, como citado pela Agência A.

Em todas as entrevistas, tanto de criativos quanto com pessoas da área de gestão, foi possível perceber diversas referências a uma mudança que está acontecendo há algum tempo,

Perspectivas em Gestão \& Conhecimento, João Pessoa, v. 9, n. 3, p. 35-46, set./dez. 2019. 
segundo os respondentes, na área da comunicação, marketing e publicidade, que seriam decorrentes do advento da tecnologia e redes digitais e seus impactos nas formas de consumo, relacionamento e até mesmo no ambiente organizacional.

Torna-se difícil afirmar que a análise se refere à realidade em um cenário macro, baseando-se em uma amostra tão reduzida de sua população, embora rica em diferentes perspectivas, visto histórico, porte e estrutura organizacional tão diversificada. Indica-se para tanto a necessidade de ampliação dessa amostra para a obtenção de outros subsídios que embasem um retrato mais aproximado da realidade do mercado publicitário. A relevância do presente estudo consiste em fomentar discussões acerca desse mercado, questionando velhas práticas e visualizando a concepção de alternativas que destaquem a capacidade absortiva e sua importância para potencializar o pensamento inovativo, por meio do compartilhamento de experiências e valorização do conhecimento externo.

\section{REFERÊNCIAS}

BARDIN, Laurence. Análise de conteúdo, Edições 70, Lisboa. Portugal, LDA, 288p, 2009.

BEN-OZ, Chanan; GREVE, Henrich R. Short-and long-term performance feedback and absorptive capacity. Journal of Management, v. 41, n. 7, p. 1827-1853, 2015.

COHEN, Wesley M.; LEVINTHAL, Daniel A. Absorptive capacity: A new perspective on learning and innovation. Administrative science quarterly, v. 35, n. 1, p. 128-152, 1990.

DAGHFOUS, Abdelkader. Absorptive capacity and the implementation of knowledge-intensive best practices. SAM Advanced Management Journal, v. 69, n. 2, p. 21, 2004.

DE MASI, Domenico. Criatividade e grupos criativos: fantasia e concretude. Tradução: Léa Manzi, Yadir Figueiredo. Rio de Janeiro: Sextante, 2005.

EBERS, Mark; MAURER, Indre. Connections count: How relational embeddedness and relational empowerment foster absorptive capacity. Research Policy, v. 43, n. 2, p. 318-332, 2014.

ENKEL, Ellen; HEIL, Sebastian. Preparing for distant collaboration: Antecedents to potential absorptive capacity in cross-industry innovation. Technovation, v. 34, n. 4, p. 242-260, 2014.

FLORIDA, Richard. A ascensão da classe criativa. Porto Alegre: L\&PM, 2011.

HENNESSEY, B. A., \& AMABILE, T. M. Creativity. The Annual Review of Psychology is online at psych.annualreviews.org, 2010.

HUGHES, Mathew et al. Social capital and learning advantages: A problem of absorptive capacity. Strategic Entrepreneurship Journal, v. 8, n. 3, p. 214-233, 2014.

LANE, Peter J.; KOKA, Balaji R.; PATHAK, Seemantini. The reification of absorptive capacity: A critical review and rejuvenation of the construct. Academy of management review, v. 31, n. 4, p. 833-863, 2006. 
LEAL-RODRÍGUEZ, Antonio L. et al. Absorptive capacity, innovation and cultural barriers: A conditional mediation model. Journal of Business Research, v. 67, n. 5, p. 763-768, 2014.

Patterson, W.; Ambrosini, V. Configuring absorptive capacity as a key process for research intensive firms. Technovation, 36, 77-89, 2015.

SIMONTON, Dean Keith. Creativity: Cognitive, personal, developmental, and social aspects. American psychologist, v. 55, n. 1, p. 151, 2000.

SCHLAGWEIN, Daniel; HU, Monica. How and why organisations use social media: five use types and their relation to absorptive capacity. Journal of Information Technology, v. 32, n. 2, p. 194-209, 2017.

STERNBERG, Robert J. The nature of creativity. Creativity research journal, v. 18, n. 1, p. 87-98, 2006.

TODOROVA, Gergana; DURISIN, Boris. Absorptive capacity: valuing a reconceptualization. Academy of management review, v. 32, n. 3, p. 774-786, 2007.

YIN, Robert K. Estudo de Caso: Planejamento e métodos. Bookman editora, 2015.

WARD, Thomas B.; SMITH, Steven M.; FINKE, Ronald A. Creative cognition. Handbook of creativity, v. 189, p. 212, 1999.

ZAHRA, Shaker A.; GEORGE, Gerard. Absorptive capacity: A review, reconceptualization, and extension. Academy of management review, v. 27, n. 2, p. 185-203, 2002.

ZAHRA, Shaker A.; FILATOTCHEV, Igor; WRIGHT, Mike. How do threshold firms sustain corporate entrepreneurship? The role of boards and absorptive capacity. Journal of business venturing, v. 24, n. 3, p. 248-260, 2009.

ZOLLO, Maurizio; WINTER, Sidney G. Deliberate learning and the evolution of dynamic capabilities. Organization science, v. 13, n. 3, p. 339-351, 2002. 